\title{
Variola Minor in Coalfield Areas of England and Wales, 1921-34: \\ Geographical Determinants of a National Smallpox Epidemic that Spread Out of Effective Control
}

\author{
Matthew R Smallman-Raynor ${ }^{\mathrm{a}}$, Sarah Rafferty ${ }^{\mathrm{b}}$ and Andrew D Cliff ${ }^{\mathrm{c}}$
}

\section{$\underline{\text { Positions and affiliations }}$}

${ }^{a}$ School of Geography, University of Nottingham, University Park, Nottingham, NG7 2RD, UK. (ORCID ID: orcid.org/0000-0002-0942-7209).

${ }^{\mathrm{b}}$ School of Geography, University of Nottingham, University Park, Nottingham, NG7 2RD, UK. (ORCID ID: orcid.org/0000-0003-2286-3598).

${ }^{c}$ Department of Geography, University of Cambridge, Downing Place, Cambridge, CB2 3EN, UK. (ORCID ID: orcid.org/0000-0002-5636-0959).

Correspondence to: M R Smallman-Raynor, School of Geography, University of Nottingham, University Park, Nottingham, NG7 2RD, UK. Email: matthew.smallmanraynor@ nottingham.ac.uk. Tel.: +44 (0)115 9515427. 


\begin{abstract}
This paper uses techniques of binary logistic regression to identify the spatial determinants of the last national epidemic of smallpox to spread in England and Wales, the variola minor epidemic of 1921-34. Adjusting for age and county-level variations in vaccination coverage in infancy, the analysis identifies a dose-response gradient with increasing odds of elevated smallpox rates in local government areas with (i) medium (odds ratio $[O R]=5.32,95 \%$ Confidence Interval [95\% CI] 1.96-14.41) and high $(O R=11.32,95 \%$ CI 4.20-31.59) coal mining occupation rates and (ii) medium $(O R=16.74,95 \%$ CI $2.24-125.21)$ and high $(O R=$ 63.43, 95\% CI 7.82-497.21) levels of residential density. The results imply that the spatial transmission of variola virus was facilitated by the close spatial packing of individuals, with a heightened transmission risk in coal mining areas of the country. A syndemic interaction between common respiratory conditions arising from exposure to coal dust and smallpox virus transmission is postulated to have contributed to the findings. We suggest that further studies of the geographical intersection of coal mining and acute infections that are transmitted via respiratory secretions are warranted.
\end{abstract}

Keywords: England and Wales; binary logistic regression; coal mining; 1921-34 epidemic; medical geography; smallpox 


\section{Highlights}

- Spatial risk-modifiers for epidemic smallpox in England and Wales are examined

- The 1921-34 smallpox epidemic was centred on coal mining areas

- A dose-response gradient existed between mining occupation rates and smallpox rates

- A syndemic interaction between respiratory conditions and smallpox is postulated

- The spatial intersection of coal mining and acute infections merits further study 


\section{Introduction}

The global eradication of smallpox was one of the remarkable achievements of twentiethcentury public health medicine (Fenner et al., 1988). In October 1977, after an intensified 10year campaign against the disease, the World Health Organization (WHO) traced the last naturally occurring case of smallpox to the town of Merca in southern Somalia. Two years later, with no further cases of the disease (barring laboratory incidents) having been recorded, the WHO formally announced that the global eradication of smallpox was complete (Fenner et al., 1988). Today, authorised holdings of smallpox (variola) virus are maintained for research purposes in laboratories in Atlanta (USA) and Siberia (Russia). The fate of these remaining virus stocks is due to be decided at the Seventieth World Health Assembly in May 2017 (Arita and Francis, 2014).

The advent of a peculiarly mild form of smallpox - known as variola minor represents one of the more enigmatic episodes in the modern history of the disease (Fenner et al., 1988, pp. 315-63). Variola minor was first recognised in the latter part of the 1890s, and it was this mild form of the disease that presented particular challenges to the WHO's global eradication programme as smallpox was pushed back to the Horn of Africa in the 1970s (Fenner et al., 1988, p. 326). Few explicitly geographical studies of large-scale epidemics of the disease have been published, and the geographical determinants and drivers of variola minor in specific epidemic settings - such as inter-war England and Wales - are largely unknown (Angulo et al., 1977; Fenner et al., 1988; Splaine et al., 1974; Stocks, 1933a, b).

This paper uses small-area data for a protracted epidemic of variola minor that spread in England and Wales in the 1920s and 1930s to analyse the spread mechanisms behind the epidemic. This epidemic marked the last occurrence of smallpox as an endemicallytransmitted infection in the British Isles (Fenner et al., 1988, pp. 324-6; Smallman-Raynor and Cliff, 2012), and is a prime example of a geographically extensive smallpox epidemic 
that diffused in an uncontrolled manner in a national population with waning levels of vaccine-induced immunity (Ministry of Health, 1921, 1922-45). Adopting a retrospective cross-sectional design that encompasses the complete records of notified smallpox activity in 1,874 local government areas of England and Wales, 1921-34, our analysis demonstrates that the spread of variola minor was strongly related to spatially-localised population proximity. Close spatial packing of individuals facilitated variola virus transmission via direct contact of susceptibles with the oropharyngeal secretions of infectives, with a heightened transmission risk in coal mining areas of the country. A syndemic interaction between common respiratory conditions arising from exposure to coal dust (catarrh, chronic rhinitis, pharyngitis) and the primary transmission route of variola virus (exposure to oropharyngeal secretions) is postulated to have contributed to the spatial associations we report. This postulated interaction has implications for the investigation of coal mining in relation to a range of other acute infections that are transmitted via respiratory secretions, including diphtheria, measles, meningococcal meningitis and streptococcal diseases.

\section{Background: variola virus and the 1921-34 smallpox epidemic in}

\section{England and Wales}

\section{Nature of smallpox}

Smallpox was an acute infectious disease caused by variants of variola virus. Humans were the only reservoir of variola virus and the primary routes of smallpox transmission were through direct contact with the oropharyngeal secretions of an infected person and, less commonly, via contact with contaminated objects (fomites) such as the clothing and bedding of patients (Fenner et al., 1988; Heymann, 2015). As described by Heymann (2015, pp. 5614), a typical incubation period of 10-14 days (range: 7-19 days) gave way to a non-specific prodromal illness that was characterised by the sudden onset of fever, headache, malaise and 
prostration. After 2-4 days, a characteristic rash appeared on the face and other parts of the body that pustulated and scabbed after 3-4 weeks. The period of infectivity of a patient extended from the first appearance of skin lesions to the disappearance of virus-harbouring scabs.

\section{Clinical types and severity}

Studies of the evolutionary history of variola virus suggest that twentieth century lineages of the virus had been in existence for $~ 200$ years, and that they had evolved in tandem with extant processes of globalisation and vaccine control (Duggan et al., 2016). These lineages were associated with two recognised clinical forms of the disease: variola major and variola minor (Heymann, 2015, pp. 561-4). Variola major was the more severe form of the disease; historically, it was associated with a high case-fatality rate ( 30 percent in unvaccinated populations) and, for survivors, its sequelae included severe scarring, blindness and male infertility. Variola minor, on the other hand, was a distinctly milder form of the infection (case-fatality rate $<1$ percent) that had first come to notice in South Africa and the United States in the late nineteenth century, and which became established in some countries of the Americas, Europe and the Pacific in the early decades of the twentieth century (Fenner et al., 1988, pp. 243-3).

\section{The 1921-34 variola minor epidemic in England and Wales}

In the United Kingdom, the Vaccination Acts of 1898 and 1907 had relaxed the midnineteenth laws on the compulsory vaccination of infants so that, by 1921 , some 2.5 million or more children aged <12 years were legally exempted from vaccination in England and Wales (Ministry of Health, 1921). It was at about this time that variola minor began to establish itself as an epidemic of national proportions. From early foci in central and northeastern England in the early 1920s, the ensuing epidemic developed to a peak in 1927 when over 14,000 cases were notified (Figure 1). By the termination of the epidemic in 1934, 
a cumulative total of 81,495 cases (including 209 deaths) had been notified from 868 local government areas (Figure 2A).

\section{FIGURE 1 NEAR HERE}

FIGURE 2 NEAR HERE

Although the variola minor epidemic of 1921-34 was one of the outstanding epidemiological events in inter-war England and Wales (Ministry of Health, 1922-45), very little is known of the factors that shaped the geography of the disease (Rafferty, 2016; Smallman-Raynor and Cliff, 2012). Yet, underlying the broad geographical sweep of the epidemic (Figure 2A) were pronounced groupings of high incidence areas (Figure 2B) that lend the epidemic a distinctive spatial character. While local-area investigations pointed to the role of certain demographic (young age) and socioeconomic (residential density) factors as determinants of disease activity (Stocks, 1933a, b), the extent to which these and other factors shaped the national disease pattern in Figure 2 has yet to be determined.

\section{The coal mining connection}

Elsewhere, we have examined how the living and working conditions in communities attached to the coal mining industry - which accounted for some 7 percent of the male workforce of inter-war England and Wales (Figure 3) - conditioned the epidemic spread of one acute infectious disease (meningococcal meningitis) in the 1930s (Smallman-Raynor and Cliff, 2017). In the present paper, we examine the extent to which the same mining communities conditioned the epidemic spread of smallpox in the 1920s and 1930s (Figure 2).

Our investigation is informed by incidental press coverage of the involvement of colliery towns and villages and colliers and their families in the course of the 1921-34 epidemic (Anonymous 1923, 1924, 1926, 1927a, 1928), and by concerns expressed by senior 
government advisors over the possible impact of the great industrial dispute of 1926 on efforts to assert effective disease control in coalfield areas (Chief Medical Officer, 1927).

\section{FIGURE 3 NEAR HERE}

\section{Methods}

\section{Data}

Local government areas (metropolitan boroughs, county boroughs, municipal boroughs, urban districts and rural districts), utilised by the General Register Office (GRO) and the Census Office for the collection of epidemiological and sociodemographic data in inter-war England and Wales, form the basic spatial units of analysis in the present paper. Allowing for local administrative reorganisations that periodically resulted in the creation, abolition and redesignation of areas, some 1,930 local government areas existed at one time or another during the 14-year period of the smallpox epidemic (1921-34). Of these, 1,874 (97\%) were extant on the date of one (or both) of the United Kingdom population censuses in June 1921 and April 1931. For reasons of census data availability, all subsequent analysis is limited to this 1,874-unit sample.

\section{Epidemiological data}

To examine the geographical occurrence of smallpox in England and Wales, we draw on corrected notifications of the disease received by the GRO and published in the annual volumes of the Registrar-General's Statistical Review (Registrar-General for England and Wales, 1923-35). For a given year of the epidemic period, 1921-34, annual smallpox counts for each of the local government areas were abstracted from the Statistical Review to form 14 $($ years $) \times 1,874$ (areas) matrices of smallpox notifications and notification rates per 100,000 population. Within each disease matrix, areas were then coded according to the RegistrarGeneral's contemporary classification of regions (Registrar-General For England and Wales, 
1944). Regions are mapped in Figure 2, while smallpox notifications and notification rates per 100,000 are given for each geographical division in Table 1.

\section{TABLE 1 NEAR HERE}

\section{Occupational and sociodemographic data}

We draw on the 1921 and 1931 population censuses of England and Wales as the primary sources of occupational and sociodemographic information for the time period and spatial level under examination.

(1) Occupational data: coal mining. Taken as an average across the two censuses, some 941,100 males (and 2,700 females) were classified in Order III (Mining and Quarrying Occupations), Sub-order 1 (In Coal and Shale Mines), with coal and shale mining accounting for well over 7\% of the entire male workforce of England and Wales. For the purposes of the present analysis, information was abstracted from the censuses (Census Office, 1922-24, 1934) to yield estimates of the average male occupation rate for coal mining (expressed as a percentage proportion of the male workforce) in each of the 1,874 local government areas. Table 1 provides regional counts of the average number of males occupied in coal mining, along with the associated occupation rate and the principal coalfields in which they were employed. The principal coalfields are mapped in Figure 3.

(2) Sociodemographic data: age and density of residential occupation. Two documented epidemiological features of the 1921-34 smallpox epidemic were: (i) the elevated numbers of smallpox notifications among children and young adults aged $<25$ years (Chief Medical Officer, 1926-35; see Figure 4); and, based on a five-county study of central and northern England, (ii) the statistically significant and positive association between smallpox incidence and residential density (persons per room) in a given geographical area (Stocks, 1933b). To adjust for these two factors in the national pattern of notified smallpox activity, 
sociodemographic information was abstracted from the County Parts of the 1921 and 1931 censuses (Census Office, 1922-24, 1932-33) to yield, for each of the 1,874 local government areas under examination, average estimates of (i) the proportion of the total population that was aged $<25$ years and (ii) the number of persons per room for family dwellings.

\section{FIGURE 4 NEAR HERE}

\section{Vaccination data}

Although the Vaccination Act of 1853 mandated the compulsory vaccination of infants in England and Wales, subsequent legislation relaxed this requirement and permitted parents to obtain a certificate of exemption for a child if they believed the vaccine to be inefficacious or unsafe (Smallman-Raynor and Cliff, 2012). Geographical variations in certified exemptions from vaccination, along with the enduring issue of vaccination 'defaults' arising from failure to comply with the vaccination laws, had resulted in pronounced county-to-county variations in the vaccination coverage of younger people in the lead up to the 1921-34 smallpox epidemic (Ministry of Health, 1920, 1921).

To allow for any county effect arising from differential levels of vaccination coverage in infancy, we draw on annual summaries of the Vaccination Officer's Annual Returns as published in the Local Government Board's Report of the Medical Officer (London: HMSO) and the Ministry of Health's Annual Report (London: HMSO). Here, information relating to compliance with the vaccination laws in each county of England and Wales was used to form county-level estimates of the percentage proportion of infants who were unvaccinated (vaccination exemptions and defaults). These estimates were created as averages over consecutive birth-registration years, 1903-21, to correspond with the most vulnerable age groups (0-18 years; see Figure 4) at the time of onset of the smallpox epidemic in 1921. For each of the 1,874 local government areas under examination, these average annual estimates 
of unvaccinated infants in the parent counties (1903-21) served as a proxy marker of the county-wide level of childhood susceptibility to smallpox.

\section{Statistical analyses}

\section{Indices of disease intensity: location quotients}

To capture the geographical variability in notified rates of smallpox, area-level disease rates were indexed to the national rate using the method of location quotients (Burt et al., 2009). In general terms, the location quotient $(L Q)$ is an index for comparing the concentration of a particular phenomenon (here, notified rates of smallpox) in a given geographical area $i$ with some reference area $j$. As such, $L Q$ is a geographically-referenced version of the rate ratio in epidemiological investigations. For the purposes of the present analysis, the location quotient $L Q_{i t}$ for area $i(=1,2, \ldots, 1,874)$ and time period $t$ was defined as

$$
L Q_{i t}=r_{i t} / R_{t}
$$

where $r_{i t}$ and $R_{t}$ are, respectively, the area- and national- (England and Wales) level smallpox notification rates per 100,000 population. Values of $L Q_{i t}>1.00$ signify a higher notification rate in local area $i$ as compared to the national level, while values of $L Q_{i t}<1.00$ signify a lower notification rate. Values of $L Q_{i t}=1.00$ signify an equivalence of rates at the local and national levels.

Equation 1 was used to compute $L Q_{i t}$ for the average annual smallpox rate in the epidemic period, 1921-34. Adopting a quotient value in excess of 2.00 (that is, more than twice the national rate $R_{t}$ ) as the level to define elevated rates of disease activity, the resulting $L Q_{i t}$ were then dichotomously coded as 1 (elevated disease rates; $L Q_{i t}>2.00$ ) or 0 (non-elevated disease rates; $L Q_{i t} \leq 2.00$ ). The adoption of this binary classification was fixed by (i) an analytical preference for readily interpretable divisions of disease rates, (ii) the 
need to ensure a sufficient allocation of areas in the upper category for the purposes of logistic regression analysis and (iii) the desire to moderate for any statistical instabilities (manifesting here as $L Q_{i t} \gg 2.00$ ) in the small area data. Table 2 gives the total number of areas in each category of the binary classification, along with the number of smallpox notifications and the average annual notification rate per 100,000 population, $1921-34$. Areas with values of $L Q_{i t}>2.00$ are mapped in Figure 2B.

\section{TABLE 2 NEAR HERE}

\section{Binary logistic regression}

To determine whether area-level smallpox rates were associated with rates of male occupation in coal mining, we used binary logistic regression (Hosmer et al., 2013). The multivariate version of the binary logistic regression model can be written as

$$
\ln [\widehat{Y} /(1-\hat{Y})]=\beta_{0}+\beta_{1} X_{1}+\cdots+\beta_{k} X_{k}
$$

where $\hat{Y}$ is the probability of the response ('outcome') variable being equal to 1 and $X_{1}, \ldots, X_{k}$ are continuous or categorical predictor ('exposure') variables. The exponential functions of the coefficients $\beta_{1}, \ldots \beta_{k}$ are odds ratios $(O R)$ that provide measures of association between the response and predictor variables. In epidemiological investigations, $O R=1.00$ indicates that the predictor variable does not influence the odds of disease outcome; $O R>1.00$ indicates that the predictor variable is associated with a higher odds of outcome, while $O R<$ 1.00 indicates that the predictor variable is associated with a lower odds of outcome.

Model application. Area-level smallpox rates, coded according to the binary classification of the associated $L Q_{i t}(=0,1)$, were entered as the response variable in a binary logistic regression model with five categorical predictor variables: 
1. coal mining occupation rate, formed as a four-level variable $(0 \% ; 1-25 \% ; 26-50 \%$; $51-75 \%$ ) with non-zero categories of equal range;

2. residential density, measured as the number of persons per room for family dwellings and specified as a three-level variable $(\leq 0.70 ; 0.71-0.89 ; \geq 0.90)$;

3. county-level estimates of the proportion of infants who were unvaccinated (1903-21 birth-registration years), formed as a three-level variable ( $\leq 33 \% ; 34-54 \% ; \geq 55 \%)$;

4. estimated proportion of the population aged $<25$ years, formed as a three-level variable $(\leq 40 \% ; 41-44 \% ; \geq 45 \%)$; and

5. mining areas by coalfield, formed as an eight category variable (non-coalfield areas; Cheshire; Durham-Northumberland; Nottinghamshire-Derbyshire; South Wales; Staffordshire-Worcestershire-Warwickshire; Yorkshire; other coalfields). Here, the 'other coalfields' category includes Cumberland, Denbighshire-Flintshire, Kent and Somerset.

For predictor (1), the ordinal classification represented a balance between the allocation of substantial numbers of areas in each category of the classification and an intuitively simple division of occupation rates. For predictors (2)-(4), the lower and upper levels were defined according to the first (Q1) and third (Q3) quartiles of the respective distributions. Finally, for predictor (5), assignment of a given area was based on a male occupation rate for coal mining in excess of the national rate (that is, $>7.42$ ); areas with occupation rates below the national rate were classified as 'non-coalfield' areas. The principal coalfields are mapped in Figure 3. Table 3 gives the total number of local government areas, along with the associated population totals (1921 and 1931 census averages), assigned to each level of the five predictor variables. 
For the purposes of the modelling procedure, reference levels for the predictor variables were set as $0 \%$ (coal mining occupation rate), $\leq 0.70$ (residential density), $\leq 33 \%$ (unvaccinated infants), $\leq 40 \%$ (population aged $<25$ years), and 'non-coalfield areas' (coalfields). Model fitting was undertaken in Minitab® Version 16.2.4 (Minitab Inc., Pennsylvania). The results of the analysis are presented below as adjusted $O R$, 95\% confidence intervals $(95 \% \mathrm{CI})$ and associated $P$-values. The overall goodness-of-fit of the model was assessed using the deviance and Pearson's $\chi^{2}$ statistics. For all analyses, statistical significance was judged at the $P=0.05$ level (two-tailed test).

\section{Results}

Table 3 gives the total number of smallpox notifications, along with the average annual notification rate per 100,000 population, for each level of the five predictor variables. A gradient in (scaled) levels of smallpox activity is observed for Predictors 1-4, with notification rates increasing in sequence with the occupation rate for coal mining (Predictor 1), residential density (Predictor 2), the proportion of unvaccinated infants in the 1903-21 birth-registration years (Predictor 3) and the proportion of the population aged $<25$ years (Predictor 4). A 5- to 22-fold difference in smallpox notification rates is identified for the lowermost ('zero'/'low') and uppermost ('high') levels of each variable, with a peak disease rate (73.90 notifications per 100,000 population) in areas where coal mining represented the occupation of the majority of males $(\geq 51 \%)$. As compared to the relatively low rates of notified disease activity in non-coalfield areas (8.48 notifications per 100,00), Predictor 5 in Table 3 shows the highest notification rates to be associated with mining areas attached to the Durham-Northumberland (86.46), Nottinghamshire-Derbyshire (52.96), Yorkshire (40.40) and South Wales (35.69) coalfields. 


\section{Binary Logistic Regression}

The results of the binary logistic regression analysis are summarised in Table 4 . The table gives the adjusted $O R, 95 \% \mathrm{CI}$ and associated $P$-values for the predictor variables, along with measures of the overall goodness-of-fit of the model.

\section{TABLE 4 NEAR HERE}

The analysis identifies a dose-response gradient with increasing odds of elevated smallpox rates in areas with: (i) medium $(O R=5.32,95 \%$ CI 1.96-14.41) and high $(O R=$ $11.32,95 \%$ CI $4.20-31.59)$ coal mining occupation rates; (ii) medium $(O R=16.74,95 \%$ CI 2.24-125.21) and high $(O R=63.43,95 \%$ CI 7.82-497.21 $)$ levels of residential density; and (iii) medium $(O R=2.63,95 \%$ CI $1.05-6.63)$ and high $(O R=6.28,95 \%$ CI $2.49-15.85)$ levels of unvaccinated infants in the 1903-21 birth-registration years. Geographically, raised odds of elevated smallpox rates are identified for the Durham-Northumberland $(O R=2.87$, 95\% CI 1.18-6.96) and Nottinghamshire-Derbyshire $(O R=6.52,95 \%$ CI 2.56-16.56) coalfields, while the Cheshire $(O R=0.20,95 \%$ CI $0.05-0.77)$ and the StaffordshireWorcestershire-Warwickshire $(O R=0.15,95 \%$ CI $0.03-0.77)$ coalfields are found to have significantly deflated odds of smallpox activity. Finally, the independent effects of the age variable are limited to deflated odds in areas with medium levels of the population aged $<25$ years $(O R=0.51,95 \%$ CI $0.27-0.98)$.

\section{Discussion}

Contemporary observers of the 1921-34 smallpox epidemic were puzzled by the uneven geographical distribution of the disease in England and Wales (Figure 2). Commenting on the experience of County Durham, for example, Sir George Newman, Chief Medical Officer, expressed the view that it was "difficult to adequately account for the disproportionate prevalence of smallpox", adding that "No doubt a number of factors contributed to this 
result" (Chief Medical Officer, 1927, p. 42). In a subsequent investigation of five high incidence counties (Derbyshire, Durham, Northumberland, Nottinghamshire and the West Riding of Yorkshire), Stocks (1933b) drew attention to the role of residential density (persons per room) as an environmental determinant of smallpox activity in the constituent sets of local government areas. Consistent with the opportunities afforded by overcrowded living conditions for the heightened transmission of viruses that commonly spread via the respiratory route, Stocks observed how:

There was ... a strong tendency for an epidemic of small-pox to become established in those districts [local government areas] where the population was more densely housed more readily than in others, and also a tendency when an epidemic was established for a larger proportion of the population to be attacked where the overcrowding was greater (Stocks, 1933b, p. 309).

Extending the geographical framework of Stocks' original investigation to include all 62 counties of England and Wales, the results of binary logistic regression analysis in Table 4 identify a dose-response gradient with very high and increasing odds of elevated smallpox activity in areas with medium and high residential densities. Accepting the wide confidence intervals associated with the adjusted $O R$, our results are consistent with the sample study of Stocks and underscore the role of residential density as an area-level risk-modifier in the national pattern of notified smallpox activity, 1921-34.

Even in those local government areas with high residential densities, the 1921-34 smallpox epidemic was characterised by marked variations in notified levels of disease activity that point to the operation of additional factors in the geographical spread of variola virus. By way of illustration, the interval plot in Figure 5 compares the average annual smallpox notification rates for high residential density areas $(\geq 0.90$ persons per room) in which coal mining accounted for different proportions of the male workforce. Set against a 
baseline of 13.35 notifications per 100,000 population in high-density areas with no coal mining ( $0 \%$ occupation rate), considerably higher and increasing notification rates are identified in high-density areas where coal mining accounted for $26-50 \%$ and $\geq 51 \%$ of the male workforce. Consistent with this observation, and with incidental press reports of the involvement of colliery towns and villages and colliers and their families in the development of the epidemic (Anonymous, 1923, 1924, 1926, 1927a, 1928), we have demonstrated that the pattern of high smallpox incidence in Figure 2B was statistically associated with coal mining communities in certain areas of England and Wales. When compared to local government areas with no coal mining, Table 4 identifies a dose-response gradient with increasing odds of elevated smallpox rates in areas with increasingly higher male occupation rates for coal mining. The associations are present after adjusting for residential density, aggregate (county-level) variations in unvaccinated infants and age, and manifest as a pronounced spatial focus of high disease rates in the Nottinghamshire-Derbyshire and Durham-Northumberland coalfields.

\section{FIGURE 5 NEAR HERE}

Our analysis points to the operation of a community-level effect on smallpox incidence that intensified with the proportion of the male workforce that was engaged in the mining industry. Elsewhere, we have linked a parallel finding for the 1931-32 epidemic of meningococcal meningitis in England and Wales to: (i) the role of deep coal mines as environments favourable for the transmission of the meningococcus; and, as a corollary, (ii) the heightened potential for coal miners to act as carriers of the meningococcus into the home environment (Smallman-Raynor and Cliff, 2017). Accepting the very different aetiology and epidemiology of smallpox, syndemic effects in the transmission of variola virus may have contributed to our present findings (Singer, 2009). Specifically, it is possible that certain common occupational conditions arising from exposure to coal dust (catarrh, chronic rhinitis, 
pharyngitis), and the associated tendency for sneezing and expectoration, served to enhance the spread of disease agents that are transmitted by oropharyngeal secretions (including variola virus) within, and between, the work and home environments (Groneberg et al., 2006; Long et al., 2015; Ross and Murray, 2004). We also note that particulate matter exposures are associated with an increased risk for viral respiratory infections (Ghio, 2014), and prolonged exposure to dusty working and living environments in mining areas may have operated as a risk-modifier for the respiratory acquisition of variola virus in susceptible people of all ages. As for our earlier investigation of meningococcal meningitis, the detection of a dose-response gradient for elevated smallpox rates in Table 4 , from zero ( $\Rightarrow$ areas with no coal mining) to high ( $\Rightarrow$ areas in which coal mining was the principal male occupation), is consistent with a population-based exposure risk that is proportionate to the prevalence of miners (and, by inference, mining households) in a given area.

Whatever the role of routine working and living conditions in shaping the spread of variola minor, it is noteworthy that the rapid development of the epidemic to a peak in 192627 (Figure 1) was coincident with the largest industrial dispute to affect the British coal mining industry in the twentieth century: the national Miners' Lockout (May-December 1926) and the associated General Strike (4-13 May 1926) (Noel, 1976; Supple, 1987). Indeed, the possible connection of the prolonged miners' dispute with the smallpox epidemic was highlighted at the time by the medical press and by senior government advisors. In January 1927, for example, the British Medical Journal speculated on the possible role of the social and economic distress caused by the dispute on the epidemic spread of smallpox in the Durham-Northumberland coalfield and, by implication, other coalfield areas (Anonymous, 1927b; Barron, 2010). Even if such conditions did not actively promote the spread of smallpox in these areas, the Chief Medical Officer was cognisant of the particular difficulties that the same social and economic conditions rendered in relation to the effective control of 
the disease (Chief Medical Officer, 1927, p. 42). Our findings are consistent with these perspectives and suggest that the dispute may have contributed in some measure to the high incidence disease pattern in Figure 2B.

Mining areas with high notified rates of smallpox were not restricted to the Nottinghamshire-Derbyshire and Durham-Northumberland coalfields. Foci of areas with high smallpox rates are evident in the Yorkshire and South Wales coalfields and, to a lesser extent, in the Cheshire and Staffordshire-Worcestershire-Warwickshire coalfields (Figures 2 and 3). Interestingly, however, these coalfields were variously found to be associated with nonsignificant (Yorkshire and South Wales) or deflated (Cheshire and StaffordshireWorcestershire-Warwickshire) odds of high smallpox rates in the adjusted analysis (Table 4). While these results imply that a 'coalfield effect' was either absent or somehow protective of smallpox in some parts of the country, it is important to recognise that the disease did not invade all coalfields simultaneously. More specifically, we note that the strength of the odds ratios for coalfields in Table 4 wane as the epidemic expanded from its initial focus in the Nottinghamshire-Derbyshire coalfield (1921-) to include the Durham-Northumberland (1924-), Yorkshire (1926-), South Wales (1927-), Cheshire (1928-) and StaffordshireWorcestershire-Warwickshire (1928-) coalfields. Although some mining communities in all of these coalfield areas experienced very intense smallpox outbreaks, smallpox was seeded in proportionally fewer such communities as the spread sequence evolved. While this may reflect a modicum of success in the inter-area control of smallpox transmission as the epidemic progressed, it remains the case that all the major coalfields (with the exception of Cheshire) had substantially higher disease rates than non-coalfield areas (Table 3).

One complication of the present analysis is the differential levels of protection afforded by vaccination in the population of England and Wales at the time of the 1921-34 smallpox epidemic. Although service in the Great War had resulted in the (re-)vaccination of 
a "considerable proportion" of adult males and "many" adult females, some 2.5 million or more children aged $<12$ years were legally exempted from vaccination at the time of onset of the epidemic in 1921 (Ministry of Health, 1921, p. 12). Although the routine publication of sub-county (registration district) vaccination data ceased with the Vaccination Officers' Annual Return for 1904 (Drake, 2005; Local Government Board, 1907), and this precludes an analysis of vaccination data at the level of local government area in the present study, countylevel data reveal marked geographical variations in the proportion of children who were not vaccinated in infancy. Consistent with this observation, the present analysis has identified a distinct county-level vaccination effect, with increasing odds of elevated smallpox rates in local government areas whose parent counties had medium (34-54\%) and high $(\geq 55 \%)$ proportions of unvaccinated infants in the 1903-21 birth-registration years (Table 4).

In the absence of vaccination data at finer spatial resolutions, we cannot discount the possibility that the high incidence smallpox rates in coal mining areas resulted from a systematic deficiency in vaccination coverage in the associated communities. In as much as the last published vaccination data at the sub-county level (1904 birth-registration year) can throw any light on prevailing social attitudes to vaccination in mining and non-mining areas, we note that the proportions of infants who were vaccinated in many of the principal mining districts of Nottinghamshire, Durham and Northumberland were broadly commensurate with the estimates for the parent counties (>70 percent) and these have been adjusted for in the present analysis (Local Government Board, 1907). Importantly, these levels of vaccination coverage were substantially in excess of some non-mining districts where much more modest smallpox incidences were recorded in 1921-34 (Local Government Board, 1907). Scrutiny of surviving vaccination registers is required to shed further light on the matter.

For the purposes of logistic regression, we have adopted an intuitively simple binary classification of smallpox incidence rates, with a classification which includes substantial 
numbers of areas in each category and with the comparatively low criterion for the upper category (incidence rates greater than twice the national rate; $L Q_{i t}>2$ ) serving to moderate for the potential effects of statistical instabilities in small area data. Although not shown, sensitivity analyses using alternative binary classifications of smallpox incidence rates with the upper category variously set at $L Q_{i t}>1.00$ (that is, greater than the national rate) and $L Q_{i t}>3.00$ (greater than three times the national rate) yielded results that were substantially the same as those reported in Table 4. Likewise, ordinal logistic regression analysis with a four-level response variable $\left(L Q_{i t} \leq 1.00 ;>1.00 ;>2.00 ;>3.00\right)$ yielded parallel results, albeit with an infringement of the proportional odds assumption in one of the predictors (residential density). While consideration was given to the inclusion of interaction terms in the fitting of the binary logistic regression model in equation 2, the decision to exclude such terms was taken on the basis of their non-significance in preliminary analysis.

To simplify the interpretation of exposures in the modelling procedure, binary logistic regression was performed on a categorical division of the continuous predictors. In the absence of an epidemiological basis for the determination of thresholds, the statistical properties of the data (lower and upper quartiles) were used to define 'low' and 'high' categories for those predictors (residential density, unvaccinated infants and age) with observations that were approximately normally distributed. For the remaining continuous predictor (mining occupation rate), which was highly skewed to zero and low non-zero observations, the quartile classification was substituted for an intuitively simple categorical classification with (non-zero) categories of equal range. To check that our data-dependent categorisations had not biased the outcome of the modelling procedure, binary logistic regression was also performed using continuous data. Although not shown, this procedure yielded results that were commensurate with the findings in Table 4. 
The limitations of the present investigation include a range of considerations that relate to unmeasured and uncontrolled confounding in population-level ecological studies (Greenland and Robins, 1994; Pearce, 2000). In particular, our use of area-based data precludes any comment on individual disease cases and the nature of their connections (if any) with the local coal mining industry. While our findings in relation to coal mining have been adjusted for the potential confounding effects of certain epidemiologically relevant factors (residential density, county-level variations in vaccination coverage and young age), unrecognised and uncontrolled factors may assume relevance. For example, local studies of the coal mining area of East Dean in Gloucestershire, where an intense smallpox outbreak occurred in 1923-24, have pointed to such considerations as public perceptions of the disease, local opposition to standard control protocols and the lack of availability of isolation facilities in efforts to assert effective smallpox control (Rafferty, 2016). The extent to which these and related factors may have influenced the spread of smallpox in other mining areas of England and Wales merits further investigation.

The results that we have described are subject to the limitations of the available data. Although the notification of smallpox cases was a requirement in all local government areas throughout the time period under examination (McCormick, 1993), potential sources of error in the available records arise from errant and missed diagnoses (Ministry of Health, 192245). Many attendant physicians had never previously encountered smallpox and were unfamiliar with the characteristic symptoms of the disease (Wanklyn, 1922), while the mild nature of variola minor resulted in cases being mistaken for chickenpox and, less commonly, measles, scarlet fever and influenza (Brand, 1922; Fenner et al., 1988; Wanklyn, 1922). The deliberate concealment of smallpox patients further added to the problem of case undernotification (Ministry of Health, 1924, 1925), while anecdotal evidence suggests that many patients endured a mild bout of variola infection without ever seeking the assistance of 
medical personnel (Ministry of Health, 1926). For those cases that were notified, the publications of the Registrar-General do not include age-related information at the level of local government areas, thereby precluding the use of age-standardised disease rates in the present analysis. To handle this latter limitation, our modelling approach included an adjustment that allowed for the known young age ( $<25$ years) of many recognised cases in the 1921-34 epidemic (Figure 4).

While there is considerable literature on the health outcomes of coal mining and other 'dusty trades', much of this literature has focused on non-communicable and chronic respiratory conditions (Long et al., 2015; Ross and Murray, 2004). To our knowledge, this is the first spatial epidemiological investigation of the historical association between coal mining and smallpox. We have suggested that the observed association may have been conditioned, at least in part, by a syndemic interaction between common occupational conditions and the respiratory transmission of variola virus. This postulated interaction has wider implications for an understanding of the geographical intersection of coal mining and acute infections that are transmitted via respiratory secretions, including diphtheria, measles, meningococcal meningitis and streptococcal diseases. 


\section{Acknowledgements}

We are grateful to the anonymous referees for their helpful comments on an earlier draft of

this article. The work was supported by the Leverhulme Trust under Grant (RPG-2012-736). 
Table 1. Smallpox notifications and male occupation in coal mining, England and Wales, 1921-34.

\begin{tabular}{|l|c|c|c|c|}
\hline Region & $\begin{array}{c}\text { Local } \\
\text { government } \\
\text { areas }(n)\end{array}$ & $\begin{array}{c}\text { Smallpox notifications } \\
(1921-34) \dagger\end{array}$ & $\begin{array}{c}\text { Males occupied in } \\
\text { coal mining }\end{array}$ & Principal coalfields* \\
\hline East & 159 & $1,017 \quad(3.86)$ & $531(0.09)$ & Nottinghamshire-Derbyshire; Staffordshire- \\
\hline Midland & 333 & $19,552(20.55)$ & $214,500(9.73)$ & Worcestershire-Warwickshire \\
\hline North & 548 & $37,359(20.41)$ & $472,808(11.04)$ & $\begin{array}{l}\text { Cheshire; Cumberland; Durham-Northumberland; } \\
\text { Yorkshire }\end{array}$ \\
\hline $\begin{array}{l}\text { South East and } \\
\text { Greater London }\end{array}$ & 445 & $16,436(8.89)$ & $4,921 \quad(0.12)$ & Kent \\
\hline South West & 193 & $268(0.94)$ & $6,493 \quad(1.00)$ & Somerset \\
\hline Wales & 196 & $6,863 \quad(17.96)$ & $241,859(27.77)$ & Denbighshire-Flintshire; South Wales \\
\hline England and Wales & 1,874 & $81,495(14.65)$ & $941,112(7.42)$ & \\
\hline
\end{tabular}

Notes: $\uparrow$ Average annual notification rate per 100,000 population, 1921-34, in parentheses. National total excludes Port Health Authorities. $\$$ Male occupation rate for coal mining, expressed as a percentage proportion of the male workforce, in parentheses. All values based on averages for the 1921 and 1931 censuses. *Coalfields are mapped in Figure 3. 
Table 2. Local government areas categorised by smallpox incidence rates, England and Wales, 1921-1934

\begin{tabular}{|c|c|c|c|c|}
\hline & & & \multicolumn{2}{|c|}{ Smallpox } \\
\hline Smallpox incidence rate $\left(L Q_{i t}\right)$ & Areas $(n)$ & $\begin{array}{l}\text { Population } \\
\text { (millions) } \dagger\end{array}$ & Notifications & $\begin{array}{l}\text { Rate per } \\
100,000 \ddagger\end{array}$ \\
\hline Low $(\leq 2.00)$ & 1,695 & 34.54 & 19,167 & 3.96 \\
\hline $\operatorname{High}(>2.00)^{*}$ & 179 & 5.19 & 62,328 & 85.79 \\
\hline
\end{tabular}

Notes: $†$ Census average (1921 and 1931). $¥$ Expressed as an average annual rate, 1921-34. *Areas are mapped in Figure 2B. 
Table 3. Smallpox notification rates by category, local government areas, England and Wales, 1921-1934

\begin{tabular}{|c|c|c|c|c|}
\hline & \multirow[b]{2}{*}{ Areas $(n)$} & \multirow[b]{2}{*}{$\begin{array}{l}\text { Population } \\
\text { (millions) } \dagger\end{array}$} & \multicolumn{2}{|c|}{ Smallpox } \\
\hline & & & Notifications & $\begin{array}{l}\text { Rate per } \\
100,000 \ddagger\end{array}$ \\
\hline \multicolumn{5}{|l|}{ Predictor 1: Coal mining occupation rate } \\
\hline Zero $(0 \%)$ & 974 & 22.56 & 29,437 & 9.32 \\
\hline Low $(1-25 \%)$ & 664 & 12.80 & 18,561 & 10.36 \\
\hline Medium $(26-50 \%)$ & 123 & 2.16 & 10,627 & 35.18 \\
\hline High $(\geq 51 \%)$ & 113 & 2.21 & 22,870 & 73.90 \\
\hline \multicolumn{5}{|l|}{ Predictor 2: Residential density (persons per room) } \\
\hline Low $(\leq 0.70)$ & 406 & 3.71 & 598 & 1.15 \\
\hline Medium $(0.71-0.89)$ & 1,008 & 17.66 & 17,102 & 6.92 \\
\hline High $(\geq 0.90)$ & 460 & 18.36 & 63,795 & 24.82 \\
\hline \multicolumn{5}{|c|}{ Predictor 3: Unvaccinated infants (1903-21 birth-registration years) } \\
\hline Low $(\leq 33 \%)$ & 300 & 5.78 & 3,561 & 4.40 \\
\hline Medium (34-54\%) & 1,140 & 27.75 & 58,553 & 15.07 \\
\hline High $(\geq 55 \%)$ & 434 & 6.21 & 19,381 & 22.31 \\
\hline \multicolumn{5}{|l|}{ Predictor 4: Age (population aged $<25$ years) } \\
\hline Low $(\leq 40 \%)$ & 449 & 7.12 & 4,162 & 4.18 \\
\hline Medium $(41-44 \%)$ & 994 & 19.96 & 20,185 & 7.22 \\
\hline High $(\geq 45 \%)$ & 431 & 12.64 & 57,148 & 32.28 \\
\hline \multicolumn{5}{|l|}{ Predictor 5: Coalfield } \\
\hline Non-coalfield area & 1,497 & 32.32 & 38,359 & 8.48 \\
\hline Cheshire & 47 & 0.88 & 881 & 7.18 \\
\hline Durham-Northumberland & 65 & 1.55 & 18,786 & 86.46 \\
\hline Nottinghamshire-Derbyshire & 49 & 1.09 & 8,111 & 52.96 \\
\hline South Wales & 58 & 1.32 & 6,612 & 35.69 \\
\hline Staffordshire-Worcestershire-Warwickshire & 35 & 0.88 & 1,753 & 14.15 \\
\hline Yorkshire & 78 & 1.14 & 6,469 & 40.40 \\
\hline Other coalfields & 45 & 0.53 & 524 & 7.02 \\
\hline Total & 1,874 & 39.73 & 81,495 & 14.65 \\
\hline
\end{tabular}

Notes: $†$ Census average (1921 and 1931). Totals subject to rounding errors. $\$$ Expressed as an average annual rate, 1921-34. 
Table 4. Results of binomial logistic regression for smallpox in the local government areas of England and Wales, 1921-34

\begin{tabular}{|c|c|c|}
\hline & $\begin{array}{l}\text { Adjusted } O R \\
\quad(95 \% \mathrm{CI})\end{array}$ & $P$-value $\dagger$ \\
\hline \multicolumn{3}{|l|}{ Predictor 1: Coal mining occupation rate } \\
\hline Zero $(0 \%)$ & 1.00 & \\
\hline Low $(1-25 \%)$ & $1.73(0.98,3.05)$ & \\
\hline Medium $(26-50 \%)$ & $5.32(1.96,14.41)$ & 0.001 \\
\hline High $(\geq 51 \%)$ & $11.32(4.20,31.59)$ & $<0.001$ \\
\hline \multicolumn{3}{|l|}{ Predictor 2: Residential density (persons per room) } \\
\hline Low $(\leq 0.70)$ & 1.00 & \\
\hline Medium (0.71-0.89) & $16.74(2.24,125.21)$ & 0.006 \\
\hline High $(\geq 0.90)$ & $63.43(7.82,497.21)$ & $<0.001$ \\
\hline \multicolumn{3}{|c|}{ Predictor 3: Unvaccinated infants (1903-21 birth-registration years) } \\
\hline Low $(\leq 33 \%)$ & 1.00 & \\
\hline Medium (34-54\%) & $2.63(1.05,6.63)$ & 0.040 \\
\hline High $(\geq 55 \%)$ & $6.28(2.49,15.85)$ & $<0.001$ \\
\hline \multicolumn{3}{|l|}{ Predictor 4: Age (population aged $<25$ years) } \\
\hline Low $(\leq 40 \%)$ & 1.00 & \\
\hline Medium $(41-44 \%)$ & $0.51(0.27,0.98)$ & 0.043 \\
\hline High $(\geq 45 \%)$ & $0.94(0.48,2.05)$ & \\
\hline \multicolumn{3}{|l|}{ Predictor 5: Coalfields } \\
\hline Non-coalfield area & 1.00 & \\
\hline Cheshire & $0.20(0.05,0.77)$ & 0.019 \\
\hline Durham-Northumberland & $2.87(1.18,6.96)$ & 0.020 \\
\hline Nottinghamshire-Derbyshire & $6.52(2.56,16.56)$ & $<0.001$ \\
\hline South Wales & $0.67(0.21,2.12)$ & \\
\hline Staffordshire-Worcestershire-Warwickshire & $0.15(0.03,0.77)$ & 0.023 \\
\hline Yorkshire & $0.78(0.31,1.98)$ & \\
\hline Other coalfields & $0.20(0.04,1.06)$ & \\
\hline \multicolumn{3}{|l|}{ Goodness-of-fit } \\
\hline Deviance & \multicolumn{2}{|c|}{$\chi^{2}=114.20 ; P=0.373$} \\
\hline Pearson's $\chi^{2}$ & \multicolumn{2}{|c|}{$\chi^{2}=121.90 ; P=0.206$} \\
\hline
\end{tabular}

Note: $\uparrow$ Values of $P \leq 0.05$ shown. 


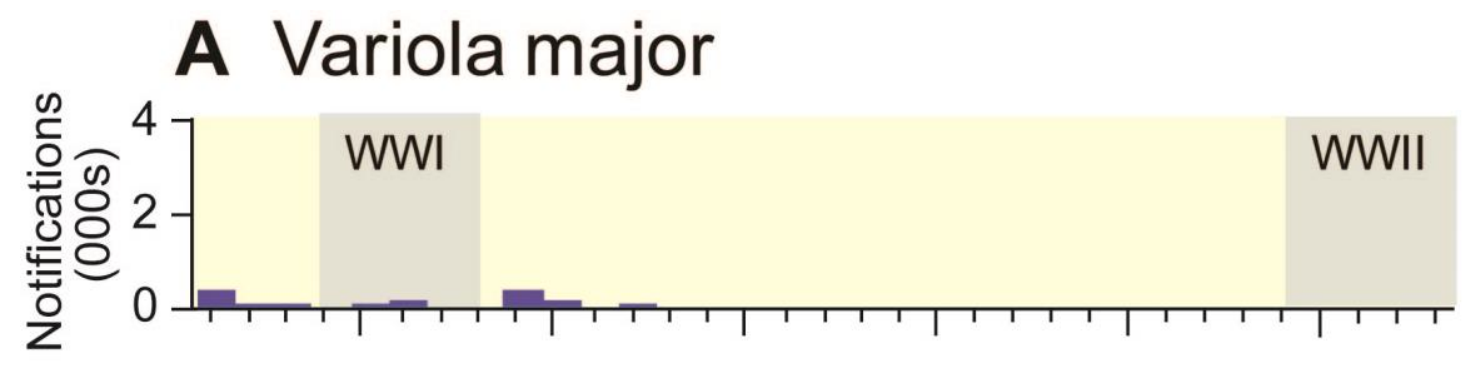

B Variola minor

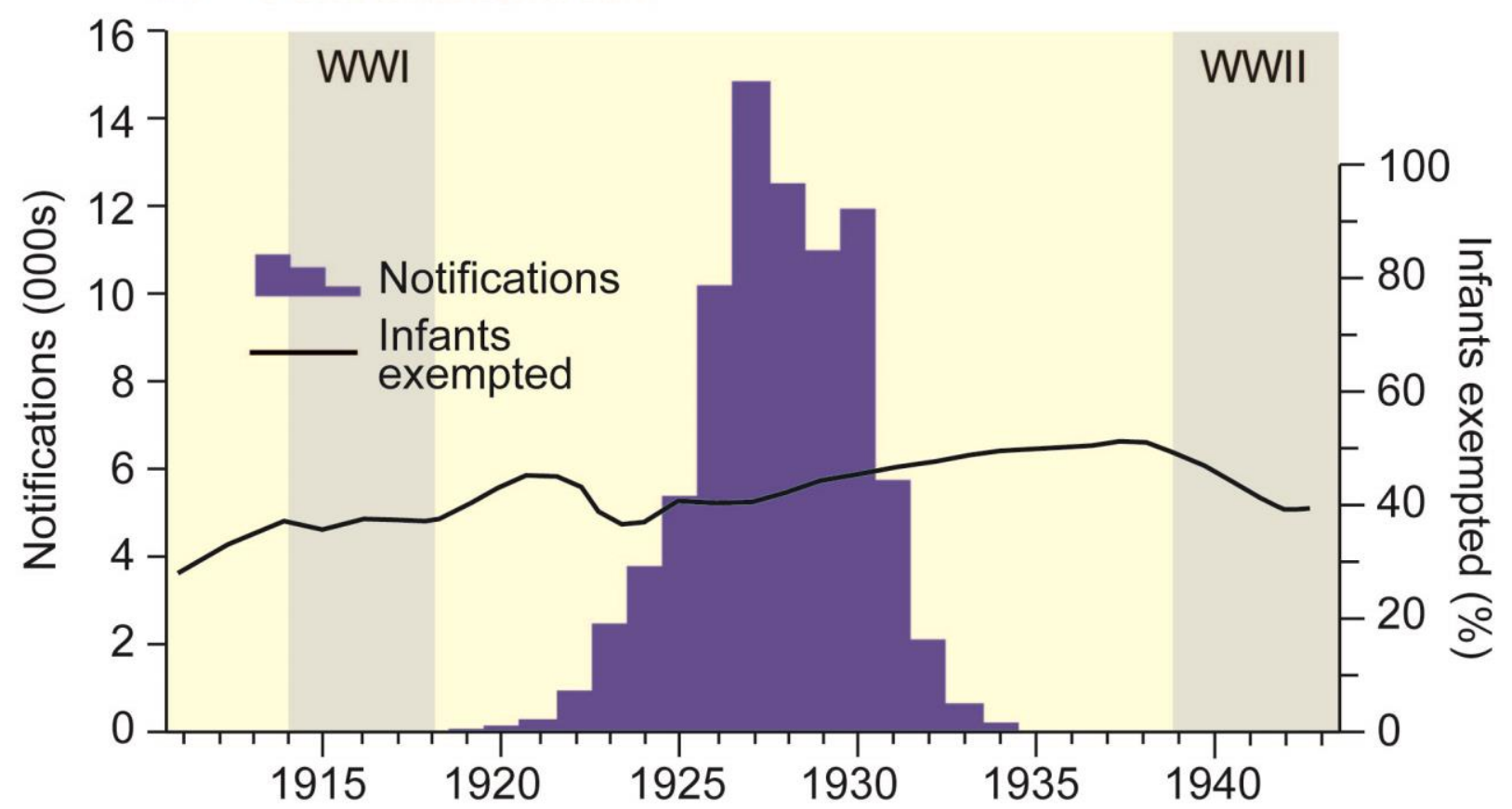

Figure 1. Smallpox notifications in England and Wales, 1911-44. The graphs plot the annual time series of notifications of (A) variola major and (B) variola minor. The line trace in graph (B) plots, by year of birth registration, the percentage proportion of infants who were exempted from vaccination under the Vaccination Acts. Sources: data from Fenner et al. (1988, Table 8.4, p. 325), Local Government Board (1919, Appendix I, p. 207) and Ministry of Health (1922-45). 

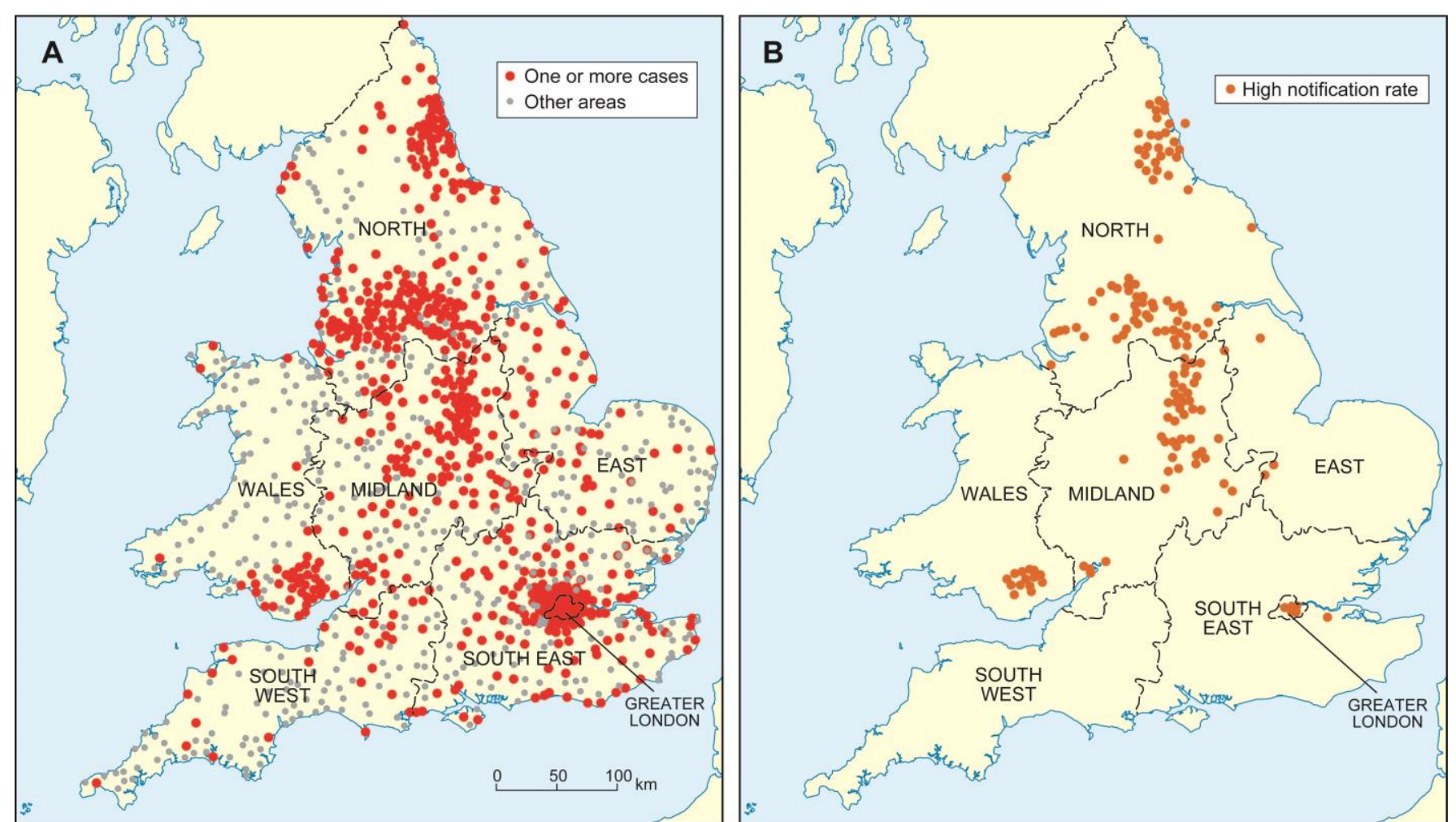

Figure 2. Smallpox in the local government areas of England and Wales, 1921-34. (A) Areas that notified one or more cases of smallpox. (B) Areas with high smallpox notification rates. Map (B) is based on location quotients $\left(L Q_{i t}\right)$ and identifies those areas in which the average annual smallpox notification rate per 100,000 population was in excess of twice the national rate (i.e. $L Q_{i t}>2.00$ ). The boundaries of the RegistrarGeneral's contemporary classification of regions are marked on each map. Source: data from Registrar-General for England and Wales (1923$35)$. 


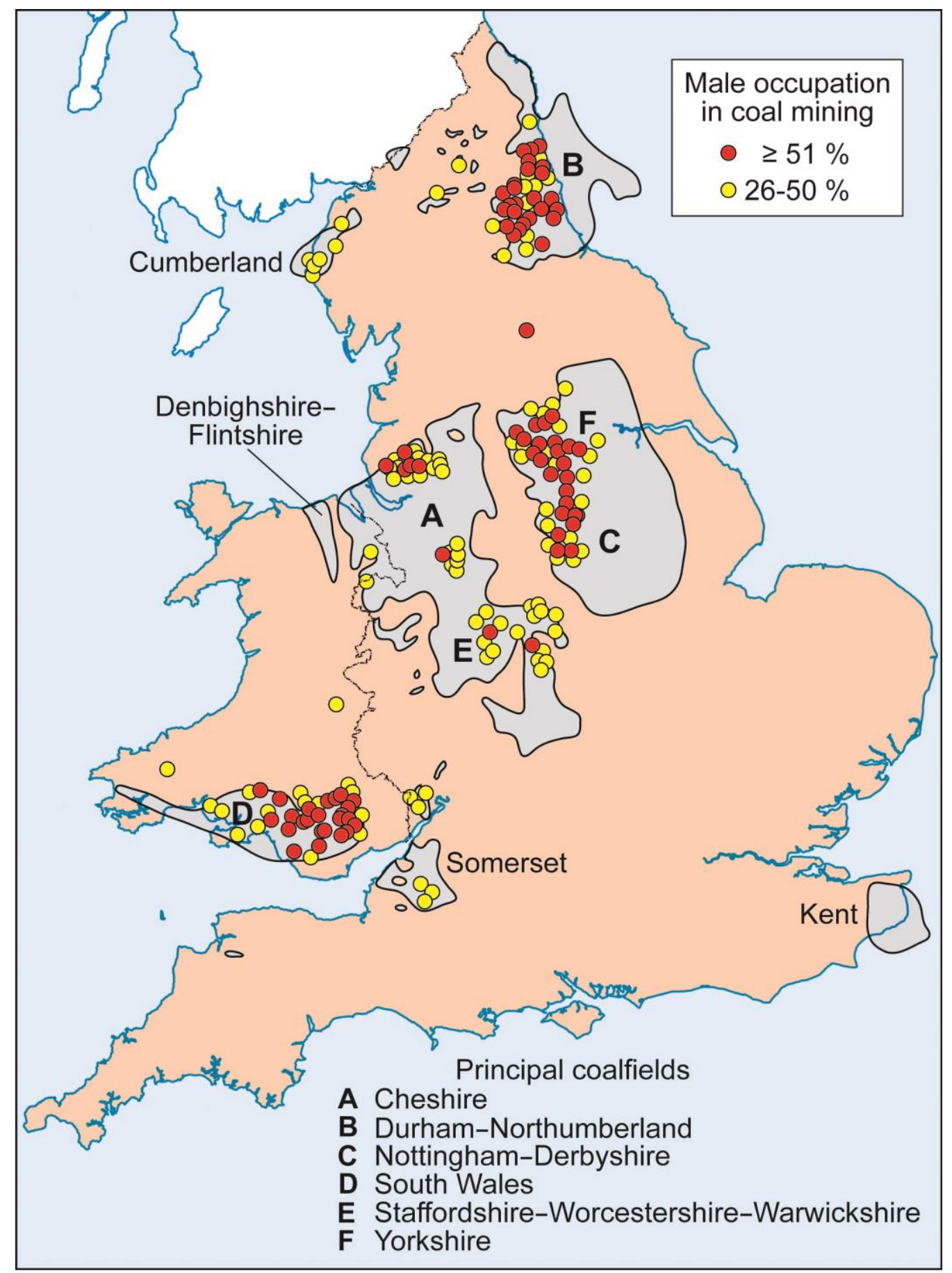

Figure 3. Coal mining districts of England and Wales, 1921-34. Local government areas with male occupation rates for coal mining of $26-50 \%$ and $\geq 51 \%$ are represented by circles. Occupation rates have been formed as an average across the 1921 and 1931 census periods. The approximate boundaries of the principal coalfields of England and Wales are indicated. Source: data from Census Office (1922-24, 1934). 


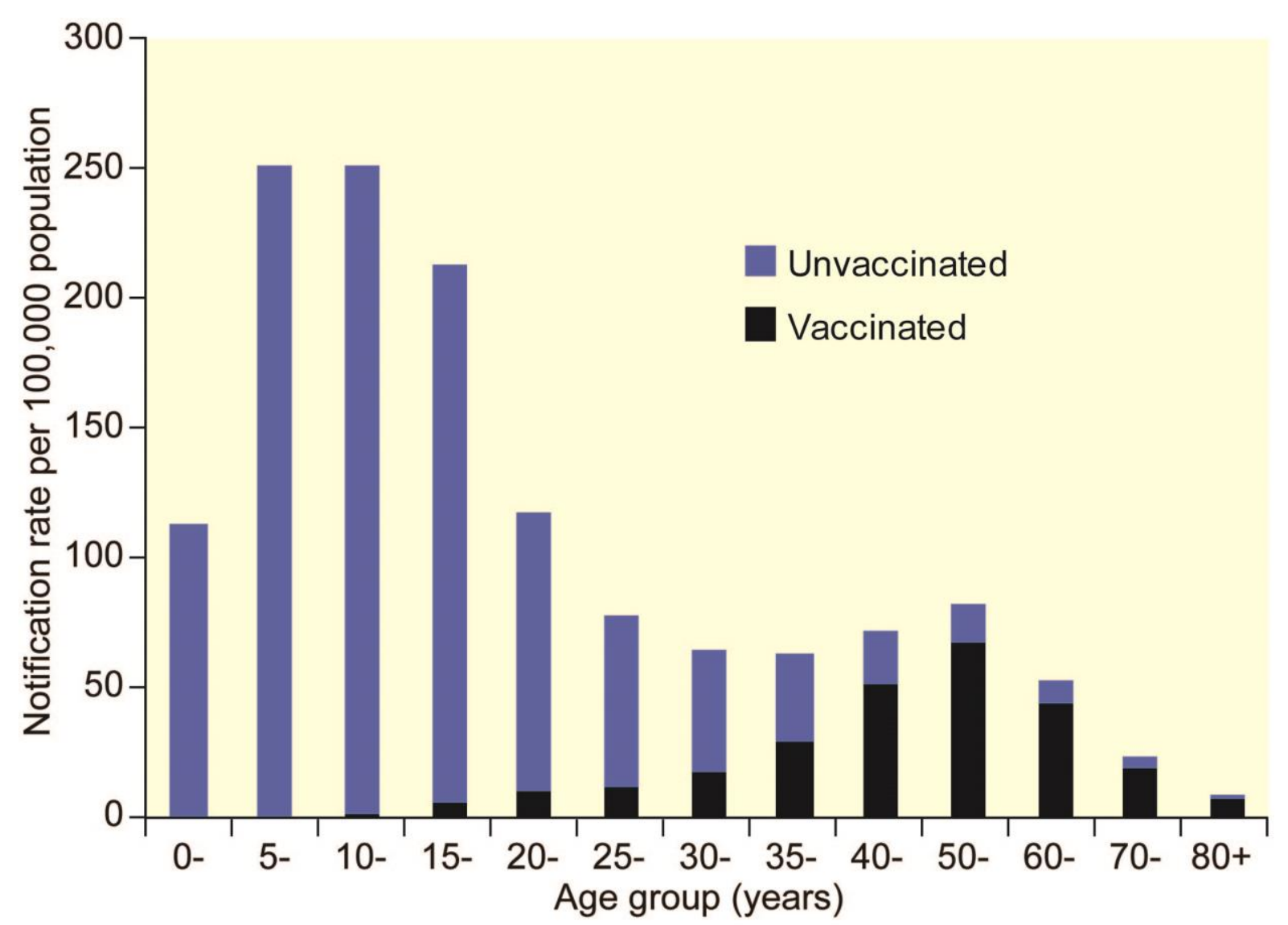

Figure 4. Age distribution of notified smallpox cases in England and Wales, 1925-33. Agespecific notification rate per 100,000 population for smallpox cases. Bars are shaded to depict the case notification rate by vaccination status. Source: data from Chief Medical Officer (1926-35). 


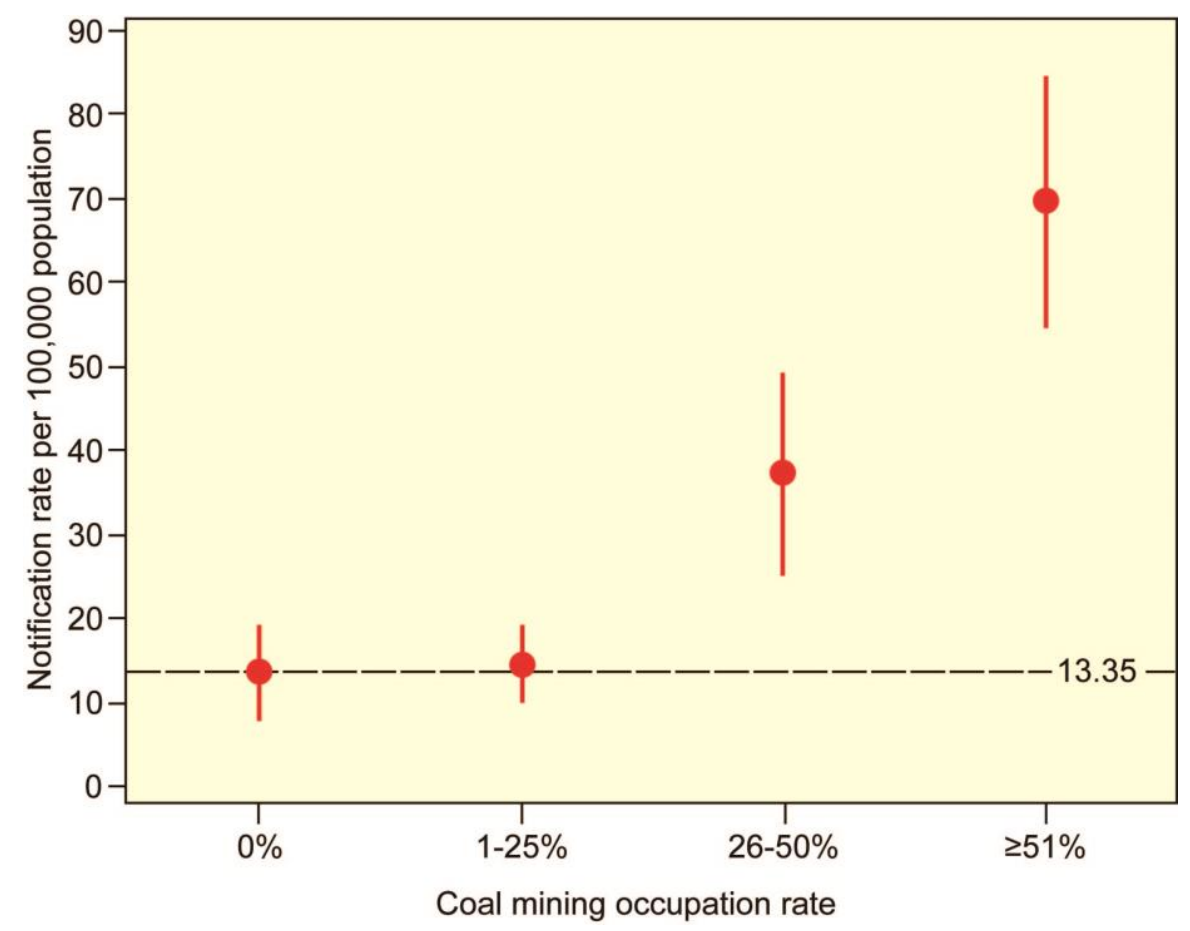

Figure 5. Interval plot of average annual smallpox notification rates in local government areas with high residential densities ( $\geq 0.90$ persons per room) in England and Wales, 1921-34. Areas are grouped by the proportion of males occupied in coal mining, The mean smallpox notification rate (circles), along with the 95\% CI (whiskers), is shown for each occupation level. The broken horizontal line, set at 13.35 smallpox notifications per 100,000 population, marks the notification rate for non-coalmining areas with high residential densities. 


\section{References}

Angulo, J.J., Haggett, P., Megale, P., Pederneiras, A.A., 1977. Variola minor in Bragança Paulista county, 1956: a trend-surface analysis. American Journal of Epidemiology $105,272-278$.

Anonymous, 1923. A death at Gloucester. The Times (London) 11 July, 12.

Anonymous, 1924. Smallpox in Derbyshire. The Times (London) 8 November, 9.

Anonymous, 1926. Increase in smallpox. The Times (London) 2 January, 10.

Anonymous, 1927a. Smallpox outbreak in Northumberland. The Times (London) 8 January, 10.

Anonymous, 1927b. Small-pox in the north of England. British Medical Journal 1, 147-149.

Anonymous, 1928. Spread of smallpox. The Times (London) 20 January, 16.

Artia, I, Francis, D., 2014. Is it time to destroy the smallpox virus? Science 345, 1010.

Barron, H., 2010. The 1926 Miners' Lockout: Meanings of Community in the Durham Coalfield. Oxford University Press, Oxford.

Brand, A.T., 1922. The differential diagnosis of small-pox and chicken-pox. British Medical Journal 2, 823 .

Burt, J.E., Barber, G.M., Rigby, D.L., 2009. Elementary Statistics for Geographers, third ed. The Guildford Press, New York.

Census Office, 1922-24. Census of England and Wales 1921. Series of County Parts. HMSO, London.

Census Office, 1932-33. Census of England and Wales 1931. Series of County Parts. Part I. HMSO, London. 
Census Office, 1934. Census of England and Wales 1931. Occupation Tables. HMSO, London.

Chief Medical Officer, 1926-35. On the State of Public Health: Annual Report of the Chief Medical Officer of the Ministry of Health. HMSO, London.

Chief Medical Officer, 1927. On the State of Public Health: Annual Report of the Chief Medical Officer of the Ministry of Health for the Year 1926. HMSO, London.

Drake, M., 2005. The vaccination registers: what they are and what can we learn from them? Local Population Studies 74, 36-53.

Duggan, A.T., Perdomo, M.F., Piombino-Mascali, D., Marciniak, S., Poinar, D., Emery, M.V., Buchmann, J.P., Duchêne, S., Jankauskas, R., Humphreys, M., Golding, G.B., Southon, J., Devault, A., Rouillard, J.-M., Sahl, J.W., Dutour, O., Hedman, K., Sajantila, A., Smith, G.L., Holmes, E.C., Poinar, H.N., 2016. 17 th $^{\text {th }}$ century variola virus reveals recent history of smallpox. Current Biology 26, 3407-3412.

Fenner, F., Henderson, D.A., Arita, I., Jesek, Z., Ladnyi, I.D., 1988. Smallpox and Its Eradication. World Health Organization, Geneva.

Ghio, A.J., 2014. Particle exposures and infections. Infection 42, 459-467.

Greenland, S., Robins, J., 1994. Ecologic studies - biases, misconceptions, and counterexamples. American Journal of Epidemiology 139, 747-760.

Groneberg, D.A., Nowak, D., Wussow, A., Fischer, A., 2006. Chronic cough due to occupational factors. Journal of Occupational Medicine and Toxicology 1:3 doi:10.1186/1745-6673-1-3.

Heymann, D.L., 2015. Control of Communicable Diseases Manual, twentieth ed. APHA Press, Washington DC. 
Hosmer, D.W., Lemeshow, S., Sturdivant, R.X., 2013. Applied Logistic Regression, third ed. Wiley, Hoboken.

Local Government Board, 1907. Thirty-fifth Annual Report of the Local Government Board. Supplement Containing the Report of the Medical Department for 1905-06. HMSO, London.

Local Government Board, 1919. Forty-eighth Annual Report of the Local Government Board, 1918-19. Supplement Containing the Report of the Medical Department for 1918-19. HMSO, London.

Long, J., Stansbury, R.C., Petsonk, E.L., 2015. Small airways involvement in coal mine dust lung disease. Seminars in Respiratory and Critical Care Medicine 36, 358-365.

McCormick, A., 1993. The notification of infectious diseases in England and Wales. Communicable Disease Report. CDR Review 3, R19-25.

Ministry of Health, 1920. First Annual Report of the Ministry of Health, 1919-1920. HMSO, London.

Ministry of Health, 1921. Small-pox and Vaccination. Reports on Public Health and Medical Subjects. No. 8. HMSO, London.

Ministry of Health, 1922-45. Annual Report of the Ministry of Health. London: HMSO.

Ministry of Health, 1924. Fifth Annual Report of the Ministry of Health, 1923-1924. HMSO, London.

Ministry of Health, 1925. Sixth Annual Report of the Ministry of Health, 1924-1925. HMSO, London.

Ministry of Health, 1926. Seventh Annual Report of the Ministry of Health, 1925-1926. HMSO, London. 
Noel, G., 1976. The Great Lock-out of 1926. Constable, London.

Pearce, N., 2000. The ecological fallacy strikes back. Journal of Epidemiology and Community Health 54, 326-327.

Rafferty, S., 2016. Epidemic Smallpox in England and Wales, 1920-35: Variola Minor Transmission, with Special Reference to Gloucestershire, 1923-24. School of Geography, University of Nottingham, BA (Hons) Dissertation.

Registrar-General for England and Wales, 1923-35. The Registrar-General's Statistical Review of England and Wales. HMSO, London.

Registrar-General for England and Wales, 1944. The Registrar-General's Statistical Review of England and Wales for the Year 1939 (New Annual Series, no. 19). Tables. Part I. Medical. HMSO, London.

Ross, M.H., Murray, J., 2004. Occupational respiratory disease in mining. Occupational Medicine 54, 304-310.

Singer, M., 2009. Introduction to Syndemics: A Systems Approach to Public and Community Health. Jossey-Bass, San Francisco.

Smallman-Raynor, M.R., Cliff, A.D., 2012. Atlas of Epidemic Britain: A Twentieth Century Picture. Oxford University Press, Oxford.

Smallman-Raynor, M.R., Cliff, A.D., 2017. Deep coal mining and meningococcal meningitis in England and Wales, 1931-38: ecological study, with implications for deep shaft mining activities worldwide. Health and Place, in review.

Splaine, M., Lintott, A.P., Angulo, J.J., 1974. On the use of contour maps in the analysis of spread of communicable disease. Journal of Hygiene (London) 73, 15-26. 
Stocks, P., 1933a. On the spread of small-pox in partially vaccinated communities. Part I. The Stepney epidemic of variola minor, 1929-30. Annals of Eugenics 5, 192-233.

Stocks, P., 1933b. On the spread of small-pox in partially vaccinated communities: Part II. Variola minor in Durham and neighbouring counties, 1922-31. Annals of Eugenics 5, $302-310$.

Supple. B., 1987. The History of the British Coal Industry. Volume 4. 1913-1946. The Political Economy of Decline. Clarendon Press, Oxford.

Wanklyn, W. McC., 1922. Small-pox diagnosis. British Medical Journal 2, 1045-1046. 